\title{
Reform of Teaching Content and Method in Vegetable Horticulture
}

\author{
Shaohui Wang, Rui Yang, Jihong Cheng, Chaojie Liu, Li Mei \\ Plant Science and Technology College, Beijing University of Agriculture, Beijing 102206, China
}

\begin{abstract}
Reform of teaching content and method in Vegetable Horticulture is discussed in this paper. In order to cultivate the comprehensive and innovative ability of the horticulture majored students, we emphasized the use of various teaching methods, enhancing of practice teaching, and deepening of the teaching contents.

Index Terms - Vegetable horticulture, teaching, contents, methods, reforms

\section{Introduction}

Vegetable Horticulture is a compulsory course for an undergraduate majoring in Horticulture. The contents mainly including the interrelation of vegetable growth and development laws with environments, the technical principle of vegetable seedling, breeding and cultivation, the management methods, as well as the construction of vegetable base. It is an applied discipline that is based on both theory and practice. The undergraduates in 21 st century should have creativity, practical ability and pioneering consciousness[1]. Only by substantive reforming the teaching contents and methods of Vegetable Horticulture can we adapt to the new trend of agricultural development and meet the requirements for undergraduates majored in agricultural science.

\section{Constantly Deepening the Teaching Contents in Order to Keep up with the Vegetable Technological Development Tendency}

Olericulture is developing rapidly; the new technologies and varieties are emerging constantly. It is important for teachers to timely update the contents during their teaching Vegetable Horticulture. By keeping up with the vegetable technological development frontier, the newest academic thoughts can be delivered to students. At present, organic agriculture development is elevated to a higher strategic level by various countries in the world. A great opportunity for the development of organic agriculture in China is created by the access to WTO and the 2008 Olympic Games held in Beijing. In recent years, as the urban modern agriculture in Beijing has been greatly developed, ecological agriculture, tourism agriculture and sightseeing agriculture become increasingly popular. Due to the fact that the water resources in China is in alarming shortage and vegetable production requires plenty of water, it is essential to introduce the knowledge about organic vegetables, pollution-free vegetables, vegetables for Olympic games, soilless culture, industrial seedling, grafting, quality control of vegetable products and water-saving agriculture in theory courses so as to enrich the teaching contents. Text book, reference book, professional journals, multimedia courseware, internet resources are the supplements for teaching contents. The teachers in the curriculum teams will take part in domestic and overseas academic conferences of horticulture and vegetable expositions, and then deliver the new academic thoughts obtained from the conferences to students in order to broaden their horizons. For example, upon knowing that the theme of the 27th International Horticulture Congress is global horticultural diversity, harmony and unity, the students are full of confidence in the discipline in which they are trained.

\section{Enhancing Practical Teaching Combined with Vegetable Industry Development in Beijing Suburbs}

Practice teaching in Vegetable Horticulture is the important step of horticulture teaching process. It is to consolidate and develop the theoretical contents already learnt through the production practice, to strengthen the perceptual knowledge, to improve students' comprehensive quality, and to train students' practical and innovation ability. Since the horticulture curriculum system is reformed and the course credit system is implemented, the hours of practice teaching in Vegetable Horticulture is reduced from 10 days to 4 days. For the sake of improving the teaching efficiency in the limited practical teaching hours, methods such as optimizing practice contents and carefully selecting the practice location can be used.

The practice contents, which include the categories and cultivation features of soilless culture vegetables, the analysis of greenhouse vegetables' plantation structure and the survey of plantation techniques, the establishment of vegetable production base and formulation of production procedures, the current status and development strategies of exported vegetables, are chosen based on the current development of vegetable industry in Beijing Suburbs.

There are highly efficient industrialized agriculture-demonstration parks in practice locations such as Daxing Changziying Vegetable Technology Demonstration Park, Mentougou Yongdingzhen Bikun Planting Center, and Shunyi Sangao Technology Demonstration Park. Students are given the chance to have a clear understanding of modern vegetable production mode for all weathers without seasonal effect, which adopts industrialized production and implements the intensification operation. Other practice locations include Liuminying Unpolluted Organic Vegetable Technology Demonstration Park which is the first ecological agriculture village in China, Shunyi Special Vegetable Base along the river, Mentougou Longquanwujie Xuyushui Mountain Wild Vegetable Planting Base, Changping Golden Six Rings Olympic Vegetable Base, Yanqing Kangzhuang Xiaofengying 
Village with achievements in anti-season sales of continental vegetables, 40 thousand square meters Badaling vegetable wholesale market in the northwest region of Beijing and its fresh-keeping storehouse that stores 6 kilotons of vegetables. In these bases, students can further understand the technical safety regulations of vegetable production, the process of vegetable precooling in production place and the vegetable renovating of commercialization; and realize what is the contract vegetable and exported vegetable, how vegetable production bases are built and operated, and how vegetable productions are carried out given the shortage in land, water, energy resources. The persons who have good knowledge of technology, management and business are needed during the construction of new countryside in China. Therefore, it is necessary for students to not only attach importance to study the high yield and high quality production technology, but also understand the establishment of production, supply and marketing service system for each base, and understand the development status of related industries such packaging, transportation, storage and catering that drove by the vegetable production and sales. Moreover, the concepts of management and business should be instilled into the minds of students so as to make them fully aware of the huge potential of vegetable industries. These informative practices both consolidate students' theoretical knowledge and enhance their professional thinking.

\section{Using Flexible and Diverse Teaching Methods to Motivate the Learning Desires of Students}

The core of scientific development concept is human orientation. During the teaching reform in colleges and universities in China, insisting on human-oriented ideology is the basis for the concept of scientific development ${ }^{[2]}$. The idea that the teacher plays the leading role and students are the main subject should be emphasized in the whole teaching process. It is also essential to make students participate in teaching activities and motivate their learning desires. For example, before the experiment of vegetable species identification, each student is asked to preview the content and then research for relevant information about the vegetable. In the experiments, each student need to introduce the botanical characteristics of one specific vegetable in the vegetable sample park, such as edible part, nutrient value and cultivation characteristics to other students in class, who will ask questions and make supplements. Finally, teacher commented on each student and explained the key points. Furthermore, the teacher should emphasize that preview, study and review are equally important for learning during teaching, and keep asking questions could help students to consolidate the knowledge what they learned and evaluate how they learned which could be part of exams. In vegetable grafting experiments, after instructing the students to master the basic grafting method, the teacher should encourage students to explore new grafting method by themselves. These practice experiments cultivated the students' abilities of searching, collating and summarizing the information, the language expression ability, the problem-solving ability, the innovation ability and thus fully aroused their enthusiasm on studying.

\section{What Else Can the Teaching Reform Strengthen in the Future?}

Self-study ability is important for adapting to the social changes in information era. It is vital to perfect the exam database establishment, explore for the bilingual teaching mode, set up the Internet-based teaching platform of Vegetable Horticulture in the teaching reform. This can bring broader self-study space to students.

\section{References}

[1] Ming Chen. Study for Establishing the Three-Dimensional Teaching System of Horticultural Plant Breeding, Journal of higher Education of Southwest University of Science and Technology, 2007(2): 76-78.

[2] Xiangming Hu, Yafen Hu. Discussions of the Human-oriented Education Concept and the Higher Education Reform, Beijing Education (Higher Education Version), 2008 (2): 34-36. 